\title{
A new test for combined Ca-leaching and sulphate resistance of cementitious materials
}

\author{
Florian R. Steindl 1,*, Andre Baldermann ${ }^{1}$, Isabel Galan ${ }^{1}$, Marlene Sakoparnig ${ }^{2}$, Martin Dietzel ${ }^{1}$, and Florian Mittermayr ${ }^{2}$ \\ ${ }^{1}$ Graz University of Technology, Institute of Applied Geosciences, Rechbauerstraße 12, 8010 Graz, Austria \\ ${ }^{2}$ Graz University of Technology, Institute of Technology and Testing of Building Materials, Inffeldgasse 24, 8010 Graz, Austria
}

\begin{abstract}
Limitations in the understanding of chemical key controls on concrete damaging mechanisms exacerbate predictions on the long-term performance and durability of cementitious materials. Therefore, the scope of the project "ASSpC - Advanced and Sustainable Sprayed Concrete" is to obtain a better mechanistic understanding of the processes underlying deleterious chemical attacks. The herein presented alternative test, loosely following the regulations of the German Building Authority (DIBt) testing procedure (the so-called SVA test) for sulphate resistance, investigates the resistance of concrete mixes with high levels of limestone substitution $(35 \%, 50 \%$ and $65 \%)$ against sulphate attack in a $10 \mathrm{~g} \mathrm{~L}^{-1} \mathrm{Na}_{2} \mathrm{SO}_{4}$ solution at ambient temperature. Powdered samples were used in favour of prisms or drill cores to accelerate alteration reactions and to eliminate variations in microstructure or porosity. Based on throughout chemical and mineralogical characterisation of the experimental solutions and solid materials, we identified and traced several mineral reactions taking place in a chronological order: (1) dissolution of portlandite and Ca-leaching from C-S-H started immediately at the beginning of the experiments and provided the physicochemical conditions favourable for (2) the precipitation of massive calcite and ettringite during the advanced stage of chemical attack. Ongoing changes in the aqueous composition indicate that C-S-H dissolves incongruently and may be transformed into Si-bearing hydrogarnet. The amount of precipitated ettringite is apparently controlled by the availability of calcium, sulphate and aluminium and the precipitation rate correlates with the superplasticiser demand of the concrete mixes and with the $\mathrm{pH}$ of the solution during the nucleation and crystal growth stages, respectively. Our test allows distinguishing between competing reaction paths and kinetics and is capable to provide new insights into concrete damaging mechanisms in sulphate-loaded aqueous environments.
\end{abstract}

\section{Introduction}

Concrete in contact with sulphate-bearing solutions is prone to suffer from sulphate attack. External sulphate attack is associated with the formation of secondary ettringite $\quad\left[\mathrm{Ca}_{6}\left[\mathrm{Al}(\mathrm{OH})_{6}\right]_{2}\left(\mathrm{SO}_{4}\right)_{3} \cdot 26 \mathrm{H}_{2} \mathrm{O}\right], \quad$ gypsum $\left[\mathrm{Ca}\left(\mathrm{SO}_{4}\right) \cdot 2 \mathrm{H}_{2} \mathrm{O}\right]$ and thaumasite $\left[\mathrm{Ca}_{3} \mathrm{Si}(\mathrm{OH})_{6}\left(\mathrm{SO}_{4}\right)\left(\mathrm{CO}_{3}\right) \cdot 12 \mathrm{H}_{2} \mathrm{O}\right]$. This form of sulphate attack often results in severe microstructural and mechanical damage of the concrete [1-3]. Investigating the mechanisms linked to expansive sulphate attack and its hazardous effect on concrete stability as well as determining important durability parameters has been an effort for a long time. However, the connection between the amount and type of newly formed expansive phases and the measured expansion of mortar prisms and drill cores remains unclear. This is probably because of different crystallization paths and related variations in the precipitation rate and crystal growth rate of secondary gypsum and ettringite [4,5]. Indeed, the formation of ettringite is well-known to induce strong crystallisation pressure in small pores causing an initial (mechanical) weakening of the cement matrix and subsequent expansion during the later stage of the attack together with gypsum [6]. The timing and quantity of gypsum vs. ettringite neo-formation, however, is controlled by kinetic parameters (presence of accelerators/inhibitors, type/amount of superplasticiser used etc.) and especially by the degree of supersaturation of the pore solution with respect to these minerals.

A large number of test methods has been developed to determine the resistance of concrete against the expansive form of sulphate attack [7]. Some efforts also exist to develop new accelerated test methods [8]. However, most test methods are based on measuring and interpreting the expansion of prisms and drill cores after immersion in a highly-concentrated sulphate solution for several months. Under such accelerated test conditions, the observed expansion is likely due to a combination of chemical and physical parameters (e.g. mineralogy, total porosity, pore size distribution, specific surface area, permeability), however, the individual contribution of these parameters on the durability of concrete cannot be resolved by these tests. Thus, finding a way to eliminate the physical influences and testing solely the chemical susceptibility of concrete against sulphate attack seems

* Corresponding author: florian.steindl@tugraz.at 
to be a promising approach to systematically describe and quantify environmental key controls and fundamental reaction pathways and rates linked to the formation of secondary, expansive phases. In this contribution, we introduce an alternative test for powdered samples and a novel multi-proxy approach, which are suitable for investigating the chemical resistance of concrete made of cements with a high level of limestone substitution against sulphate attack.

\section{Materials and Methods}

\subsection{Materials and mix design}

The tested sample set consists of a reference mortar mix (CEM 100\%) and 5 limestone-rich mortar mixes labelled as CEM 35\% LL1, CEM 65\% LL1, CEM 50\% LL2, CEM 50\% LL3 and CEM 50\% LL4, where the number refers to the amount of limestone substitution for cement (in percent) and LL1-4 denominate certain limestone types. The mineralogy and important physical/mechanical parameters of the limestone types used are given in Table 1. Note that LL1 consists of almost pure calcite $\left[\mathrm{CaCO}_{3}\right](\sim 98 \mathrm{wt}-\%)$, while LL2-4 contain less calcite $(\sim 77-80$ wt- $\%$ ) but higher amounts of quartz, feldspar and clay minerals. LL2 and LL3 were taken from the same source and thus have a similar mineralogy; however, they have a different fineness. LL4 contains small amounts of cement clinker phases because it was ground in a cement mill. For the fabrication of the eco-mortars, CEM I 52.5 R with $56 \mathrm{wt} \%$ alite, $12 \mathrm{wt}-\%$ belite, $11.7 \mathrm{wt}-\%$ aluminate, $8 \mathrm{wt}-\%$ ferrite, $3 \mathrm{wt}-\%$ periclase, $4 \mathrm{wt}-\%$ anhydrite, $2.2 \mathrm{wt}-\%$ bassanite and traces of portlandite, arcanite and calcite was used. The cement had a total organic carbon content of $<0.01 \mathrm{wt}-\%$, a Blaine specific surface area of $4430 \mathrm{~cm}^{2} \mathrm{~g}^{-1}$, a density of $3.16 \mathrm{~g} \mathrm{~cm}^{-1}, \mathrm{a} \mathrm{d}_{25}$ of $1.9 \mu \mathrm{m}$, a $\mathrm{d}_{50}$ of $6.2 \mu \mathrm{m}$ and $\mathrm{a}_{75}$ of $14.1 \mu \mathrm{m}$. The mix design used is presented in Table 2. Details on the casting procedure and the mineralogical and chemical composition of the eco-mortars and reference mortar are presented in [2]. The water/powder ratio was set to 0.50 for the reference mix and 0.35 for the limestone-rich mixes, utilising a polycarboxylate ether (PCE) based superplasticiser and a standard CEN quartz sand with a maximum grain size of $2 \mathrm{~mm}$.

\subsection{Sample preparation and test procedure}

Cores were drilled from the innermost part of the waterstored samples in order to prevent an influence from already altered outer layers. The drill cores were dried in an oven at $40^{\circ} \mathrm{C}$. This relatively low temperature was chosen to reduce the risk of alteration of the hydrated cement phases during the drying process. The samples were then crushed manually and powdered using a disk mill. The use of powdered samples in favour of cast prisms or drill cores eliminates the effect of microstructure (i.e. spatial distribution of hydrated phases, permeability and porosity) on the durability of concrete and enhances rate/velocity of the chemical attack mechanisms mentioned above.

For the developed test procedure, $20 \mathrm{~g}$ of each powder sample were immersed in $400 \mathrm{ml}$ of a $10 \mathrm{~g} \mathrm{~L}^{-1} \mathrm{Na}_{2} \mathrm{SO}_{4}$ solution, prepared from water-free $\mathrm{Na}_{2} \mathrm{SO}_{4}$ and Milli-Q water (liquid/solid ratio $=20$ ). From the onset of the mixing process until one hour of reaction time (and prior to the fluid sampling), the suspension was homogenized using a magnetic stirrer run at 150 rpm. After 10 seconds, 1, 4, 15 and 30 minutes, 1, 2 and 6 hours and 1, 2, 3 and 7 days the $\mathrm{pH}$ value and the electric conductivity (EC) were determined at $25{ }^{\circ} \mathrm{C}$. At these times, about $2 \mathrm{ml}$ of the suspension were sampled with a syringe and the liquid extracted by passing it through a $0.45 \mu \mathrm{m}$ acetate cellulose membrane filter. The

Table 1. Mineralogical and physical characterisation of the limestone types used, modified from [2]. See text for explanations.

\begin{tabular}{|lc|cccc|}
\hline Component & Unit & LL1 & LL2 & LL3 & LL4 \\
\hline Alite C 3 S M3 & & - & - & - & $2.7^{*}$ \\
Belite b-C2S & & - & - & - & $0.7^{*}$ \\
Calcite & & 97.5 & 79.7 & 77.5 & 77.4 \\
Dolomite & & 1.3 & - & - & 4.8 \\
Quartz & & 0.4 & 13.6 & 15.3 & 7.6 \\
Feldspar & {$[\mathrm{wt} \%]$} & - & 1.0 & 1.4 & 1.7 \\
Illite/Muscovite & & 0.7 & 4.6 & 4.8 & 4.5 \\
Kaolinite & & 0.1 & 0.6 & 0.6 & 3.2 \\
Dioctahedral smectite & & - & - & - & 0.9 \\
Chlorite & & - & 0.5 & 0.4 & - \\
SUM & & 100.0 & 100.0 & 100.0 & 100.0 \\
\hline Total organic carbon & {$\left[\mathrm{wt}^{-} \%\right]$} & $<0.01$ & 0.12 & 0.09 & $<0.01$ \\
$\begin{array}{l}\text { Blaine specific surface } \\
\text { area }\end{array}$ & {$\left[\mathrm{cm}^{2} \cdot \mathrm{g}^{-1}\right]$} & 4200 & 4600 & 8000 & 5000 \\
$\begin{array}{l}\text { BET specific surface } \\
\text { area }\end{array}$ & {$\left[\mathrm{cm}^{2} \cdot \mathrm{g}^{-1}\right]$} & 7790 & 42790 & 55390 & 95520 \\
$\mathrm{~d}_{25}$ & {$[\mu \mathrm{m}]$} & 3.9 & 3.5 & 1.8 & 2.5 \\
$\mathrm{~d}_{50}$ & {$[\mu \mathrm{m}]$} & 12.4 & 13.6 & 4.9 & 8.1 \\
$\mathrm{~d}_{75}$ & {$[\mu \mathrm{m}]$} & 31.7 & 31.5 & 19.6 & 31.6 \\
Density & {$\left[{\left.\mathrm{g} \cdot \mathrm{cm}^{-3}\right]}\right.$} & 2.71 & 2.69 & 2.67 & 2.68 \\
\hline
\end{tabular}

Table 2. Mix design of the mortar samples under investigation (reproduced from [2]).

\begin{tabular}{|c|c|c|c|c|c|c|c|}
\hline Component & Unit & $\begin{array}{l}\text { CEM } \\
100 \%\end{array}$ & $\begin{array}{l}\text { CEM } \\
35 \% \\
\text { LL1 }\end{array}$ & $\begin{array}{l}\text { CEM } \\
65 \% \\
\text { LL1 }\end{array}$ & $\begin{array}{l}\text { CEM } \\
50 \% \\
\text { LL2 }\end{array}$ & $\begin{array}{l}\text { CEM } \\
50 \% \\
\text { LL3 }\end{array}$ & $\begin{array}{l}\text { CEM } \\
50 \% \\
\text { LL4 }\end{array}$ \\
\hline $\begin{array}{l}\text { CEM I } \\
52.5 \mathrm{R}\end{array}$ & [wt-\%] & 100 & 65 & 35 & 50 & 50 & 50 \\
\hline $\begin{array}{l}\text { Limestone } \\
\text { (LL1-4) }\end{array}$ & [wt-\%] & 0 & 35 & 65 & 50 & 50 & 50 \\
\hline $\begin{array}{l}\text { Total cement } \\
\text { content }\end{array}$ & {$\left[\mathrm{kg} \cdot \mathrm{m}^{-3}\right]$} & 513 & 611 & 597 & 604 & 604 & 604 \\
\hline CEM I $52.5 \mathrm{R}$ & {$\left[\mathrm{kg} \cdot \mathrm{m}^{-3}\right]$} & 513 & 397 & 209 & 302 & 302 & 302 \\
\hline $\begin{array}{l}\text { Limestone } \\
\text { (LL1-4) }\end{array}$ & {$\left[\mathrm{kg} \cdot \mathrm{m}^{-3}\right]$} & 0 & 214 & 388 & 302 & 302 & 302 \\
\hline Water & {$\left[\mathrm{kg} \cdot \mathrm{m}^{-3}\right]$} & 256 & 214 & 208 & 211 & 211 & 211 \\
\hline $\begin{array}{l}\text { Super- } \\
\text { plasticizer }\end{array}$ & {$\left[\mathrm{kg} \cdot \mathrm{m}^{-3}\right]$} & 1.6 & 2.8 & 2.8 & 4.0 & 3.8 & 3.5 \\
\hline Paste volume & {$\left[\mathrm{L} \cdot \mathrm{m}^{-3}\right]$} & 419 & 420 & 420 & 420 & 420 & 420 \\
\hline $\begin{array}{l}\text { CEN sand } 0 / 2 \\
\mathrm{~mm}\end{array}$ & {$\left[\mathrm{~kg} \cdot \mathrm{m}^{-3}\right]$} & 1539 & 1536 & 1536 & 1537 & 1537 & 1537 \\
\hline $\begin{array}{l}\text { Water/cement } \\
\text { ratio }\end{array}$ & {$[-]$} & 0.50 & 0.54 & 0.99 & 0.70 & 0.70 & $0.70 *$ \\
\hline $\begin{array}{l}\text { Water/powder } \\
\text { ratio }\end{array}$ & {$[-]$} & 0.50 & 0.35 & 0.35 & 0.35 & 0.35 & 0.35 \\
\hline
\end{tabular}


liquid samples were then diluted with either $\mathrm{HNO}_{3}$ or Milli-Q water for subsequent major, minor and trace elemental analyses. After 7 days of reaction time, the experiments were terminated. The solid residue was separated by filtration through a $0.45 \mu \mathrm{m}$ membrane filter (Wattman) and washed with Milli-Q water until the filtrate had an EC value of $<1000 \mu \mathrm{S} / \mathrm{cm}$. The received solid fraction was dried for 7 days at $40^{\circ} \mathrm{C}$.

\subsection{Instruments for solid and liquid analyses}

The sample powders before and after the alteration experiments were characterized for changes in mineralogy, geochemistry and specific surface area. Chemical quantification of major and minor element contents was realized using X-ray fluorescence analysis (XRF) on a Philips PW 2404 spectrometer, with an estimated analytical precision of $\pm 0.5 \mathrm{wt}-\%$. X-ray diffractometry (XRD) for mineral identification and quantification was performed on a PANalytical X'Pert PRO diffractometer utilizing a Co X-ray tube operated at $40 \mathrm{kV}$ and $40 \mathrm{~mA}$. Samples were prepared with the toploading technique. Measurements were done from 4 to $85^{\circ} 2 \theta$ at a step size of $0.008^{\circ} 2 \theta$ and $40 \mathrm{~s}$ count time per step. The patterns were analysed using Rietveld refinement with the PANanalytical X'Pert Highscore Plus software suite (version 2.2e) and its implemented pdf-4 database. The specific surface area was determined on dried $\left(100^{\circ} \mathrm{C}\right.$ for $\left.24 \mathrm{~h}\right)$ aliquots by the multi-point adsorption BET method with a Micrometrics FlowSorb II 2300 and a $\mathrm{He}(69.8)-\mathrm{N}_{2}(30.2)$ mixture as the carrier gas. The analytical uncertainty of the $\mathrm{N}_{2}$-BET values is \pm $10 \%$.

The aqueous concentrations of major cations $\left(\mathrm{Na}^{+}\right.$, $\left.\mathrm{K}^{+}, \mathrm{Mg}^{2+}, \mathrm{Ca}^{2+}\right)$ and anions $\left(\mathrm{SO}_{4}^{2-}, \mathrm{Cl}^{-}\right)$in the liquid samples were analysed by ion chromatography (IC) performed on a Dionex ICS 3000 with an analytical error of $<3 \%$. A Perkin ElmerOptima 8300 inductively coupled plasma optical emission spectrometer (ICPOES) was used to determine trace elemental concentrations $\left(\mathrm{Sr}^{2+}, \mathrm{Al}\right.$ and $\mathrm{Si} ; \mathrm{Al}$ and $\mathrm{Si}$ were measured as total $\mathrm{Al}$ and $\mathrm{Si}$ in solution, hereafter referred to as $\mathrm{Al}_{\mathrm{aq}}$ and $\mathrm{Si}_{\mathrm{aq}}$, respectively) on acidified aliquots (analytical error $<5 \%$ ). During the experiment online $\mathrm{pH}$ and EC measurements were conducted using a WTW Multi350i instrument equipped with a SenTix41 and a TetraCon325 electrode. It has to be noted that the error for the $\mathrm{pH}$ measurements increases from \pm 0.03 to \pm 0.2 for a $\mathrm{pH}<10$ to $>12$.

The aqueous speciation of the solutions, the $\mathrm{CO}_{3}{ }^{2-}$ and the $\mathrm{OH}^{-}$concentrations, the charge balances and the saturation degrees (SI) of relevant mineral phases were calculated using the PHREEQC software code (version 3.1.5-9133) in combination with a customized Lawrence Livermore National Laboratory (LLNL) and CEMDATA07 database (e.g [9]) at the experimental pH and temperature.

\section{Results and Discussion}

\subsection{Solid-phase characterization}

A compilation of the results of XRD, XRF and BET analyses of concrete samples before and after the alteration is presented in Table 3. The variations in the chemical and mineralogical composition of the unreacted samples mostly reflect small changes in the degree of limestone substitution for cement (Table 2) and in the composition of the limestone powders (Table 1). Altered samples all show a decrease in the amount of $\mathrm{CaO}$ as well as an increase in the amounts of sulphur (analytically given as $\mathrm{SO}_{3}$ ) and loss-on-ignition (LOI), which indicates $\mathrm{Ca}$-leaching and formation of sulphate and carbonate minerals. Mineralogically, the occurrence of neo-formed ettringite together with an increase in the calcite content, a strong decrease in the amorphous phase content and the disappearance of portlandite, gypsum and cement clinker phases (alite and belite) in the reacted versus unreacted samples can be noted (Table 3 ). Only trace amounts $(<0.5 \%)$ of alite and belite were present in the samples before the test, indicating almost complete hydration. CEM 35\% LL1, CEM 65\% LL1 and CEM 50\% LL4 show comparatively small amounts $(\sim 3-4 \mathrm{wt}-\%)$ of ettringite in the altered samples, whereas CEM 100\%, CEM 50\% LL2 and CEM 50\% LL3 show ettringite contents above $7 \mathrm{wt}-\%$. The neo-formation of fine-sized ettringite and (to a lesser extent) calcite crystals is clearly indicated by an increase in the $\mathrm{N}_{2}$-BET specific surface area after 7 days of reaction time. As expected, precipitation of thaumasite was not observed, because short reaction times and temperatures above $20{ }^{\circ} \mathrm{C}$ inhibit thaumasite formation. Also, no evidence for the precipitation of gypsum or AFm phases was found, suggesting that the gain in the sulphur content in the altered samples corresponds to the precipitated ettringite. This finding is in line with the positive, linear correlation $\left(\mathrm{R}^{2}=0.95, \mathrm{n}=6\right)$ between the sulphur gain in the solids (Table 3 ) and the contemporaneous removal of $\mathrm{SO}_{4}{ }^{2-}$ ions from solutions observed over the course of 7 days (see section 3.2 and Figure 1). The latter provides further evidence that no significant amounts of further sulphate-containing phases have precipitated in the considered time frame.

\subsection{Chemical evolution of the experimental solutions}

The aqueous concentrations of $\mathrm{K}^{+}, \mathrm{Ca}^{2+}, \mathrm{Si}_{\mathrm{aq}}, \mathrm{Al}_{\mathrm{aq}}, \mathrm{Sr}^{2+}$, $\mathrm{SO}_{4}{ }^{2-}, \mathrm{CO}_{3}{ }^{2-}$ and $\mathrm{Cl}^{-}$varied systematically over the course of the experiments, whereas the $\mathrm{Na}^{+}$ concentration remained unchanged $\left(3200 \pm 100 \mathrm{mgl}^{-1}\right)$. $\mathrm{K}^{+}, \mathrm{Sr}^{2+}$ and $\mathrm{Cl}^{+}$showed a strict trend towards higher concentrations in solution along the test period. In contrast, $\mathrm{Ca}^{2+}, \mathrm{CO}_{3}{ }^{2-}$ and, to a smaller degree, $\mathrm{Si}_{\mathrm{aq}}$ showed increasing concentrations during the initial test period ( $<2$ hours), reaching a maximum value at about 6 hours and decreasing strongly afterwards until the end of the experiments. This behaviour is indicative of fast liberation of $\mathrm{Ca}^{2+}$ ions and silicic acid from portlandite 
dissolution and leaching of cement hydrates at the beginning of the experiments, followed by absorption of atmospheric $\mathrm{CO}_{2}$ into the strongly alkaline solutions, and subsequent formation of calcite, ettringite and, possibly, Si-bearing hydrogarnet $\left[\mathrm{Ca}_{3} \mathrm{Al}_{2}\left(\mathrm{SiO}_{4}\right)_{x}(\mathrm{OH})_{4(3-\mathrm{x})}, 0<\mathrm{y}<3\right]$ after a certain supersaturation degree with respect to these phases in the liquid was reached. Accordingly, $\mathrm{Al}_{\text {aq }}$ and $\mathrm{SO}_{4}{ }^{2-}$ concentrations displayed a strictly decreasing trend, suggesting ongoing removal from solution and incorporation into neo-formed ettringite. The temporal changes in the aqueous concentrations of $\mathrm{Ca}^{2+}, \mathrm{Al}_{\mathrm{aq}}, \mathrm{Si}_{\mathrm{aq}}$ and $\mathrm{SO}_{4}{ }^{2-}$ over time are shown in Figure 1. Note further that the $\mathrm{pH}$ values increased from $11.6 \pm 0.2$ at the start of the experiments to $12.2 \pm 0.3$ at the end of the experiment for all samples.

The change in the aqueous concentrations provides clear evidence for the leaching/dissolution of especially highly reactive alkali hydroxides, portlandite and cement hydrates from the sample powders, which is followed by the formation of less soluble and thermodynamically more stable phases, such as calcite and ettringite (Table 3). In the light of ettringite formation, the source(s) of $\mathrm{Al}_{\mathrm{aq}}$ are of great interest, as $\mathrm{Ca}^{2+}$ and $\mathrm{SO}_{4}{ }^{2-}$ ions are rapidly provided to the solution or are readily available from the beginning of the tests. A major source of $\mathrm{Al}_{\mathrm{aq}}$ in solution is likely provided through (incongruent) dissolution of hydrated cement phases and unreacted clinker phases. However, leaching of $\mathrm{Al}$ from silicates present in the limestone powders under highly alkaline conditions cannot be ruled out. Accordingly, CEM $100 \%$ and samples containing LL2, LL3 and LL4 type limestone with a higher content of silicates showed the highest concentration of $\mathrm{Al}_{\mathrm{aq}}$ at the start of the experiments, while samples containing LL1, which comprises $<1.5 \%$ of silicates, displayed the lowest $\mathrm{Al}_{\mathrm{aq}}$ concentrations. This concurs with the low amounts of ettringite in the altered products of CEM $35 \% \mathrm{LL} 1$, CEM 65\% LL1 (and CEM 50\% LL4).

Hydrochemical modelling of the aqueous concentration data indicate that the solutions were supersaturated with respect to calcite and ettringite, but they were undersaturated with respect to gypsum and portlandite at any time throughout the experiments (Figure 2). This finding is in line with the changes observed in the mineralogy and geochemistry of the reacted samples (Table 3). Based on our results, CEM 35\% LL1, CEM 65\% LL1 and CEM 50\% LL4 showed the smallest supersaturation degrees of ettringite (probably due to their low "reactive" Al content) and thus the smallest amounts of neo-formed ettringite in the altered samples. These samples are therefore expected to show the lowest chemical susceptibility to sulphate attack. However, the formation of ettringite may also be influenced by the amount and type of superplasticiser used, the TOC content and/or other (currently unknown) kinetic parameters. Interactions between PCE-based superplasticizers and clay minerals are also possible [10], although the influence of these processes on ettringite formation remains unclear. A direct interaction (i.e. adsorption) of PCE with $\mathrm{SO}_{4}{ }^{2-}$ ions and thus an influence on the formation of ettringite can also not be excluded $[3,11]$.

Table 3. Mineralogical and chemical composition and specific surface of the initial and altered powdered samples.

\begin{tabular}{|c|c|c|c|c|c|c|c|c|c|c|c|c|}
\hline \multirow[b]{2}{*}{$\begin{array}{l}\text { Phase } \\
\text { (wt-\%) }\end{array}$} & \multicolumn{2}{|c|}{ CEM 100\% } & \multicolumn{2}{|c|}{ CEM 35\% LL1 } & \multicolumn{2}{|c|}{ CEM 65\% LL1 } & \multicolumn{2}{|c|}{ CEM 50\% LL2 } & \multicolumn{2}{|c|}{ CEM 50\% LL3 } & \multicolumn{2}{|c|}{ CEM 50\% LL4 } \\
\hline & initial & altered & initial & altered & initial & altered & initial & altered & initial & altered & initial & altered \\
\hline Feldspar & 3.2 & 2.8 & 2.9 & 2.9 & 2.6 & 2.1 & 2.0 & 1.7 & 2.4 & 2.5 & 2.0 & 2.4 \\
\hline Calcite & 2.3 & 4.2 & 6.8 & 13.7 & 16.0 & 20.2 & 10.2 & 12.9 & 11.2 & 13.2 & 10.6 & 11.9 \\
\hline Portlandite & 3.3 & - & 2.3 & - & 1.4 & - & 1.7 & - & 1.7 & - & 1.6 & - \\
\hline Alite & $<0.5$ & - & $<0.5$ & - & $<0.5$ & - & $<0.5$ & - & $<0.5$ & - & $<0.5$ & - \\
\hline Belite & $<0.5$ & - & $<0.5$ & - & $<0.5$ & - & $<0.5$ & - & $<0.5$ & - & $<0.5$ & - \\
\hline Gypsum & 1.5 & - & 1.1 & & 0.6 & - & 1.1 & - & 1.0 & - & 0.9 & - \\
\hline Ettringite & - & 8.6 & - & 3.7 & - & 2.8 & - & 7.2 & - & 7.1 & - & 3.3 \\
\hline Quartz & 73.4 & 73.8 & 71.9 & 68.6 & 69.6 & 68.3 & 71.7 & 70.5 & 70.4 & 69.0 & 71.0 & 70.8 \\
\hline Amorphous & 16.3 & 10.7 & 14.9 & 11.1 & 9.8 & 6.6 & 13.4 & 7.8 & 13.4 & 8.3 & 13.8 & 11.7 \\
\hline Sum & 100.0 & 100.0 & 100.0 & 100.0 & 100.0 & 100.0 & 100.0 & 100.0 & 100.0 & 100.0 & 100.0 & 100.0 \\
\hline $\begin{array}{c}\text { Oxides } \\
\text { (wt-\%) }\end{array}$ & initial & altered & initial & altered & initial & altered & initial & altered & initial & altered & initial & altered \\
\hline LOI & 6.5 & 7.8 & 9.8 & 10.6 & 11.0 & 10.9 & 8.4 & 9.2 & 9.2 & 9.9 & 10.0 & 10.1 \\
\hline $\mathrm{Na}_{2} \mathrm{O}$ & 0.2 & 0.2 & 0.2 & 0.2 & 0.2 & 0.2 & 0.2 & 0.2 & 0.2 & 0.2 & 0.2 & 0.2 \\
\hline $\mathrm{MgO}$ & 0.5 & 0.5 & 0.4 & 0.4 & 0.3 & 0.3 & 0.2 & 0.2 & 0.4 & 0.4 & 0.4 & 0.5 \\
\hline $\mathrm{Al}_{2} \mathrm{O}_{3}$ & 2.3 & 2.2 & 2.0 & 2.1 & 1.6 & 1.5 & 1.9 & 1.9 & 2.1 & 2.1 & 2.2 & 2.1 \\
\hline $\mathrm{SiO}_{2}$ & 75.2 & 75.3 & 70.2 & 71.0 & 71.3 & 72.1 & 73.8 & 74.6 & 71.3 & 71.8 & 72.9 & 73.3 \\
\hline $\mathrm{SO}_{3}$ & 0.7 & 1.6 & 0.5 & 0.7 & 0.3 & 0.5 & 0.5 & 1.5 & 0.4 & 1.4 & 0.4 & 0.6 \\
\hline $\mathrm{K}_{2} \mathrm{O}$ & 0.3 & 0.3 & 0.3 & 0.3 & 0.3 & 0.3 & 0.3 & 0.3 & 0.4 & 0.4 & 0.3 & 0.3 \\
\hline $\mathrm{CaO}$ & 13.1 & 11.0 & 15.6 & 13.7 & 14.3 & 13.3 & 13.4 & 11.1 & 14.7 & 12.6 & 12.2 & 11.9 \\
\hline $\mathrm{TiO}_{2}$ & 0.1 & 0.1 & 0.1 & 0.1 & 0.1 & 0.1 & 0.1 & 0.1 & 0.1 & 0.1 & 0.1 & 0.1 \\
\hline $\mathrm{Fe}_{2} \mathrm{O}_{3}$ & 1.0 & 1.0 & 1.0 & 0.9 & 0.7 & 0.7 & 1.0 & 0.9 & 1.0 & 1.0 & 1.1 & 1.0 \\
\hline Sum & 100.0 & 99.9 & 100.0 & 99.9 & 100.0 & 99.9 & 99.9 & 100.0 & 99.9 & 99.9 & 99.9 & 100.0 \\
\hline \multirow{2}{*}{$\begin{array}{l}\text { BET sp. } \\
\text { surface } \\
\left(\mathbf{m}^{2} \mathbf{g}^{-1}\right)\end{array}$} & initial & altered & initial & altered & initial & altered & initial & altered & initial & altered & initial & altered \\
\hline & 3.50 & 7.77 & 3.79 & 4.95 & 3.65 & 6.00 & 3.99 & 8.73 & 3.37 & 7.07 & 4.15 & 5.09 \\
\hline
\end{tabular}



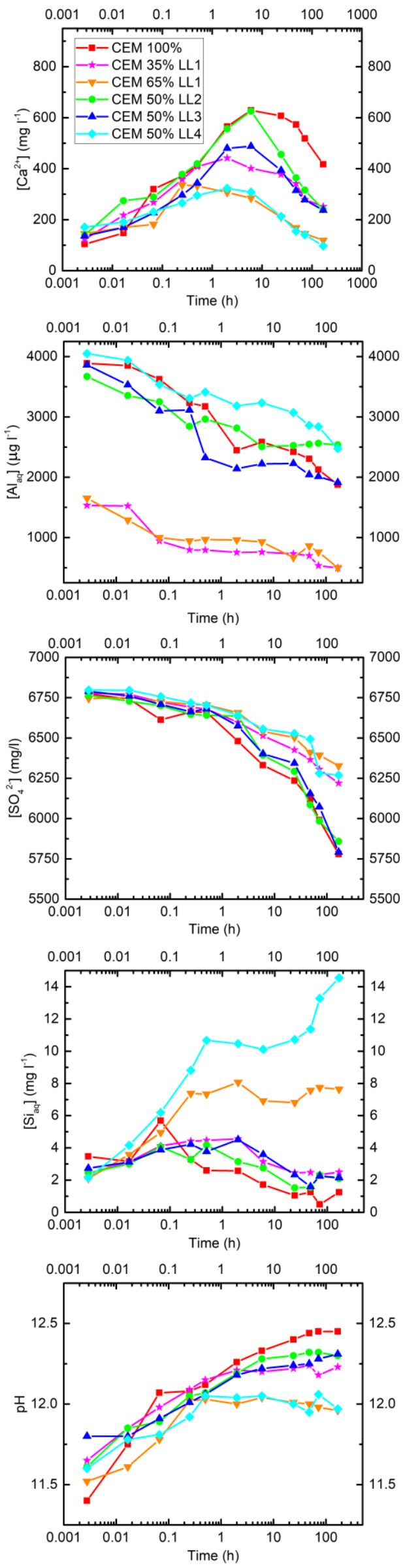

Figure 1. Change of aqueous concentrations of selected elements and $\mathrm{pH}$ over the test duration.

\subsection{Mechanisms influencing ettringite formation}

The continuous availability of $\mathrm{Ca}^{2+}, \mathrm{Al}_{\mathrm{aq}}, \mathrm{Si}_{\mathrm{aq}}$ and $\mathrm{CO}_{3}{ }^{2-}$ through ongoing dissolution, leaching and absorption reactions and the input of $\mathrm{SO}_{4}{ }^{2-}$ through an external source resemble in situ conditions. One may conclude that the formation of ettringite in this $\mathrm{SO}_{4}{ }^{2-}$-rich environment is mainly controlled by kinetic and environmental factors, such as the amount of available $\mathrm{Al}_{\mathrm{aq}}$ and $\mathrm{Ca}^{2+}$ in solution, $\mathrm{pH}$ and temperature, and the content of complexing agents such as PCE superplasticisers. However, until now it remains questionable how these factors control the apparent nucleation and crystal growth rate for ettringite. From the present data, apparent precipitation rates $\left(\mathrm{R}_{\mathrm{i}}\right)$ for ettringite were calculated according to

$$
R_{i}=1 / \nu_{\mathrm{SO}_{4}} \cdot\left(d c \mathrm{SO}_{4} / d t\right)
$$

, where $v_{\mathrm{SO} 4}$ stands for the number of moles of sulphate in one mole of ettringite, $c_{\mathrm{SO}^{4}}$ is the concentration of $\mathrm{SO}_{4}{ }^{2-}$ in the fluid and $t$ denotes time. Rates were calculated separately for the first 2 hours of the experiment and for the time span between 6 and 168 hours. These periods refer to the nucleation of ettringite crystals and to the crystal growth stage (judged by the initial increase and subsequent decrease of the SI values for ettringite, see Figure 2). The $R_{i}$ values for the nucleation stage range from $1.08 \cdot 10^{-2} \mathrm{~mol} \mathrm{~s}^{-1}$ to $3.82 \cdot 10^{-3} \mathrm{~mol} \mathrm{~s}^{-1}$ and correlate inversely with the PCE demand of the samples $\left(\mathrm{R}^{2}=0.37, \mathrm{n}=6\right)$. PCE has been shown to disturb ettringite formation by absorbing on the surface of ettringite and interacting with $\mathrm{SO}_{4}{ }^{2-}$ ions [12]. The $R_{i}$ values for the crystal growth stage vary from $3.61 \cdot 10^{-9} \mathrm{~mol} \mathrm{~s}^{-1}$ to $1.20 \cdot 10^{-9} \mathrm{~mol} \mathrm{~s}^{-1}$ and correlate linearly with the near-constant $\mathrm{pH}$ obtained after 168 hours of reaction time $\left(\mathrm{R}^{2}=0.65, \mathrm{n}=6\right)$. This suggests a control of $\mathrm{pH}$ on the crystal growth of ettringite, presumably by the increasing complexation of $\mathrm{Al}$ at higher $\mathrm{pH}$ values and a related decrease in the activity of $\mathrm{Al}$-complexes such as $\mathrm{Al}(\mathrm{OH})_{4}^{-}$and $\mathrm{Al}^{3+}$. Ettringite is stable across the whole $\mathrm{pH}$ range measured during our experiments [13]. However, at $\mathrm{pH}>12$ the solubility of $\mathrm{SiO}_{2}$ increases while $\mathrm{Al}_{\text {aq }}$ is removed from solution. On longer timescales, a decrease in the aqueous $\mathrm{Al} / \mathrm{Si}$ ratio, establishment of strong $\mathrm{pH}$ gradients at the leaching zone between concrete surface and fluid and low temperatures will shift the system from the stability field of ettringite towards thaumasite [14]. This links to the fact that thaumasite attack is often found in combination with deleterious ettringite attack and that it has been shown to form after initial ettringite formation [15].

\subsection{Transformation of hydrated cement phases}

The leaching of $\mathrm{Ca}^{2+}$ and the (incongruent) dissolution of cement clinker phases and especially portlandite and C S-H gel is evident from the initial increase of the aqueous concentrations of $\mathrm{Ca}^{2+}, \mathrm{Al}_{\text {aq }}$ and $\mathrm{Si}_{\text {aq }}$ (Figure 1), from the disappearance of alite, belite and portlandite, and a decrease in the amorphous contents determined by XRD (Table 3). However, under the present conditions 

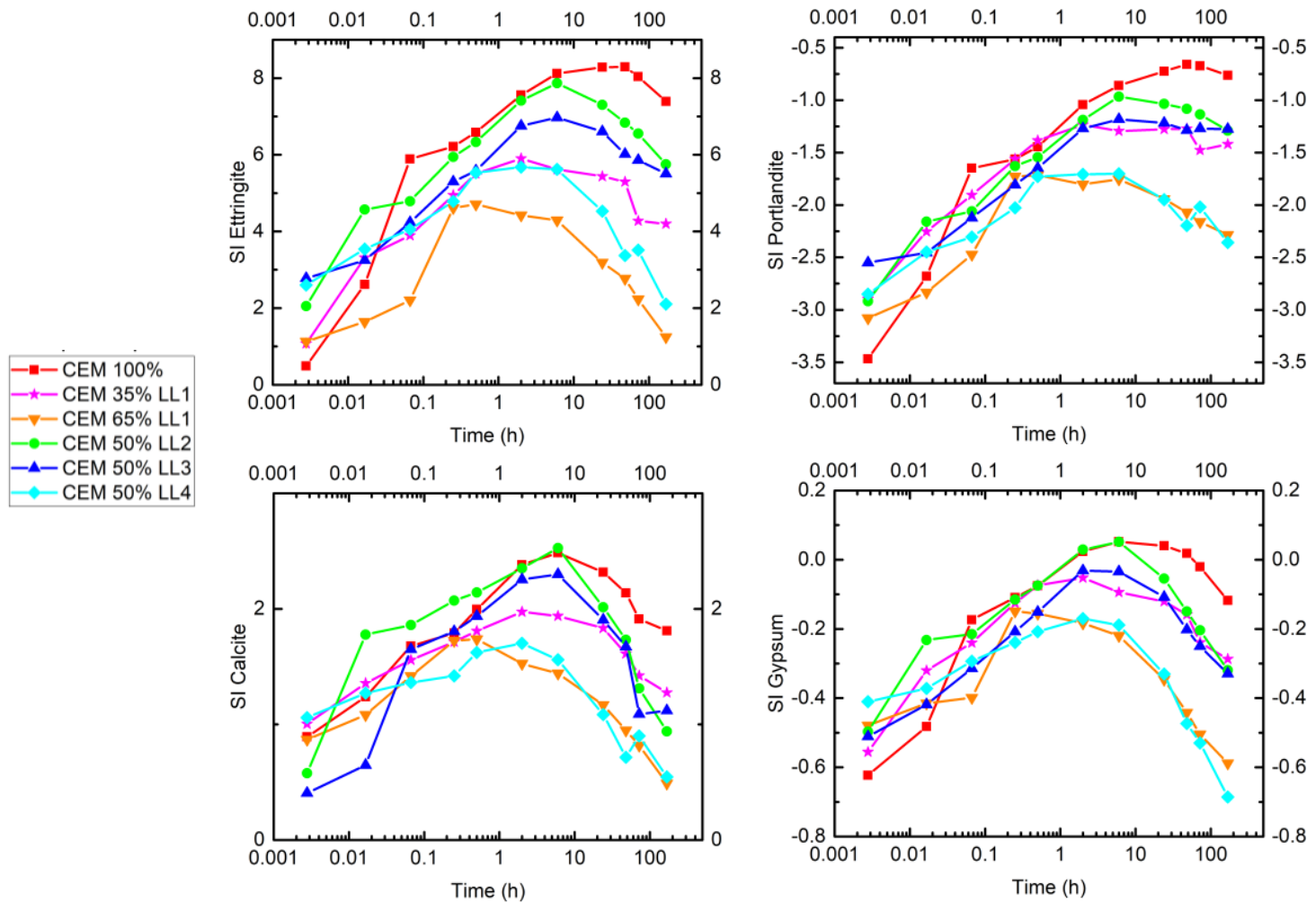

Figure 2. Change of the saturation indices of ettringite, portlandite, calcite and gypsum over the test duration.

$\mathrm{Ca}^{2+}, \mathrm{Al}_{\mathrm{aq}}$ and $\mathrm{Si}_{\mathrm{aq}}$ are scavenged by the precipitation of ettringite and calcite during the later stage of chemical attack. Furthermore, there is certain evidence for the transformation of C-S-H gel to Si-bearing hydrogarnet; a process that is likely to significantly affect the stability and reactivity of cementitious phases both on the lab and field scale.

Figure 3 shows a cross-plot of the activities of $\mathrm{H}_{4} \mathrm{SiO}_{4}(\mathrm{aq})$ against $\mathrm{Al}(\mathrm{OH})_{4}^{-} / \mathrm{OH}^{-}$in the $\mathrm{CaO}-\mathrm{Al}_{2} \mathrm{O}_{3}-$ $\mathrm{SiO}_{2}-\mathrm{H}_{2} \mathrm{O}$ phase relation diagram [16]. These phase relations indicate that Si-bearing hydrogarnet will form by a dissolution-re-precipitation mechanism from C-S-H gel in CEM 100\%, CEM 50\% LL2 and CEM 50\% LL3. Fourier Transform infrared spectroscopy (FTIR) analyses (data not shown) of the original and reacted solids revealed intense changes in the lattice vibration region (i.e. $1200-800 \mathrm{~cm}^{-1}$ due to $\mathrm{Si}-\mathrm{O}$ stretching/bending) and adsorption features indicative of $\mathrm{C}_{3} \mathrm{AH}_{6}-\mathrm{C}_{3} \mathrm{AS}_{3}$ (poorly crystallized hydrogarnet) phases in these mixes. Interestingly, these mixes also contained the highest amounts of ettringite. In essence, progressive Ca-leaching from hydrated portland cement in the presence of sulphate-bearing solutions produces conditions ideal for the formation of calcite, ettringite and Si-bearing hydrogarnet at ambient temperature and strongly alkaline $\mathrm{pH}$. The combination of these fast progressing reactions can cause chemical weakening and severe microstructural damage to the cement matrix during the early stage of sulphate attack.

\subsection{Missing links between chemical susceptibility and expansion}

CEM 35\% LL1, CEM 65\% LL1 and CEM 50\% LL4 showed the smallest chemical susceptibility to sulphate attack according to our tests. However, these are not the mixtures that performed best during the sulphate expansion tests conducted by Baldermann et al. [2]. There, the 91-days $\Delta$-expansion value is lowest for CEM $100 \%$, CEM 35\% LL1 and CEM 50\% LL2. The amount of ettringite precipitated in our experiments and the 91days $\Delta$-expansion values given by Baldermann et al. do not correlate (Figure 4). However, they show total porosities ranging from $12.6 \%$ for CEM $35 \%$ LL1 to $23.4 \%$ for CEM $50 \%$ LL2 and average pore radii ranging from $36 \mathrm{~nm}$ for CEM $50 \%$ LL4 to $68 \mathrm{~nm}$ for CEM $65 \% \mathrm{~L} 1$. This gives evidence that, as expected, besides chemical susceptibility the porosity, average pore size and pore size distribution (i.e. microstructure) strongly influence the resistance of cement to external sulphate attack. Some reasons for that can be 1) the connected porosity controls the diffusion rate of sulphate ions into the test specimens; 2 ) the progressive formation of ettringite may alter the microstructure and therefore exert a control on the further diffusion of sulphate ions; 3 ) formation of protective layers reduces the ettringite growth rate. Beyond doubt, ettringite formation in small pores $(<100 \mathrm{~nm})$ is responsible for the initial stages of expansion according to the crystallization pressure theory $[4,6]$. Further coupling of chemical resistance tests and standard test methods will provide new insights to the influences of microstructural, kinetic and 


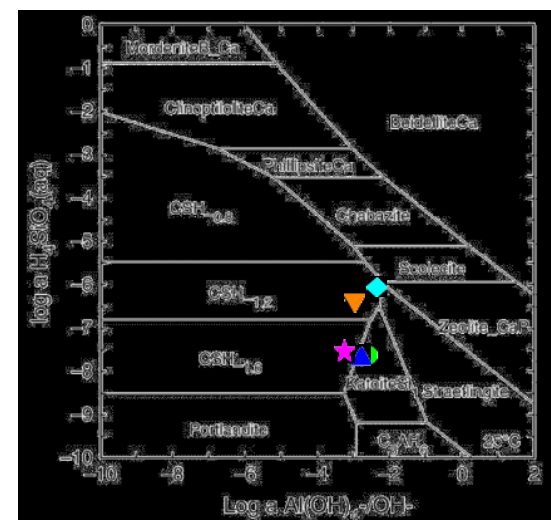

Figure 3. Dominance fields of cement hydrates (and zeolites) in the $\mathrm{a}_{4} \mathrm{SiO}_{4} v s$. a $\mathrm{Al}(\mathrm{OH})_{4} / \mathrm{OH}^{-}$diagram of Blanc et al. [16]. Si-bearing hydrogarnet is denoted as katoiteSi.

thermodynamic parameters on the sulphate durability of concrete.

\section{Conclusion}

Our paper presents a multi-method approach for elucidating the resistance of powdered concrete samples with high limestone contents (35-65 wt-\% substitution for cement) against combined Ca-leaching and sulphate attack. The most important reactions happening in a chronological order are dissolution of portlandite, cement clinker phases and gypsum, leaching of $\mathrm{Si}, \mathrm{Al}$ and $\mathrm{Ca}$ from $\mathrm{C}-\mathrm{S}-\mathrm{H}$ and aluminate phases and massive precipitation of ettringite and calcite and minor amounts of Si-bearing hydrogarnet. The amount of precipitated ettringite correlates with the PCE demand of the concrete mixes and with solution $\mathrm{pH}$ during the nucleation and crystal growth stages, respectively, and is apparently controlled by the availability of $\mathrm{Ca}^{2+}, \mathrm{SO}_{4}{ }^{2-}$ and $\mathrm{Al}_{\mathrm{aq}}$. Concretes made with high quality limestone with a low content of Al-bearing silicates (i.e. LL1) generally performed better than reference mixes (pure CEM I 52,5 R) and blended mixes containing silicate mineral impurities (i.e. clay minerals). The results from this test provide substantial insights into chemical controls and processes causing concrete damage, but they cannot be directly compared with expansion rates obtained from prisms of the same mixes. For practical purposes, both the chemical susceptibility and the physical properties of concrete should be investigated in order to elucidate its resistance against sulphate attack.

The authors gratefully acknowledge the contributions made by Katrin Inkret and Thomas Kjölbye. Funding by the Austrian Research Promotion Agency FFG within the project ASSpC (Project-No. 856080) is thankfully acknowledged.

\section{References}

[1] F. Mittermayr, A. Baldermann, M. Rezvani, S. Hainer, J. Juhart, T. Proske, 14th Int. Congr. Chem. Cem. 25-26 (2015).

[2] A. Baldermann, M. Rezvani, T. Proske, C.

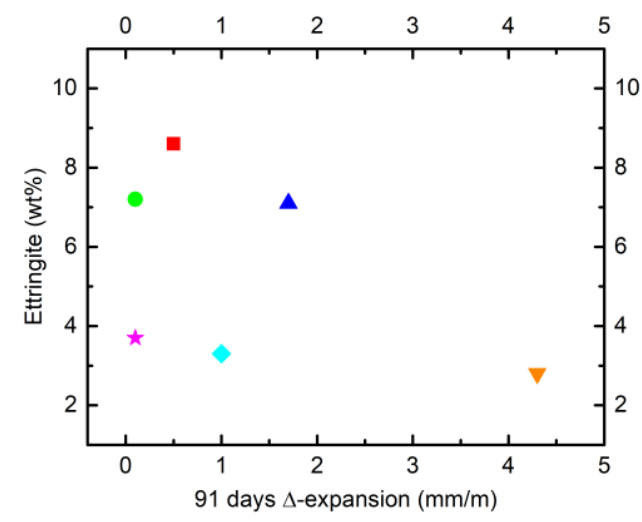

Figure 4. Correlation of the 91-days $\Delta$-expansion values given in [2] with the amount of ettringite in our altered samples.

Grengg, F. Emmerich, A.K. Stauffacher, M. Sarkopanig, F.R. Steindl, C. Baldermann, I. Galan, C.-A. Graubner, F. Mittermayr, Cem. Concr. Compos. (submitted)

[3] F. Mittermayr, M. Rezvani, A. Baldermann, S. Hainer, P. Breitenbücher, J. Juhart, C.-A. Graubner, T. Proske, Cem. Concr. Compos. 55, 364-373 (2015)

[4] W. Kunther, B. Lothenbach, K.L. Scrivener, Cem. Concr. Res. 46, 23-29 (2013)

[5] C. Yu, W. Sun, K. Scrivener, Cem. Concr. Res. 43, 105-111 (2013)

[6] W. Müllauer, R.E. Beddoe, D. Heinz, Cem. Concr. Res. 52, 208-215 (2013)

[7] K. Van Tittelboom, N. De Belie, Concr. Aggress. Aqueous Environ. Performance, Test. Model. 298-306 (2009)

[8] R. Loser, A. Leemann, Mater. Struct. 49, 1-13 (2015)

[9] D.L. Parkhurst, C.A.J. Appelo, U.S. Geol. Surv. Tech. Methods, B. 6, Chapter A43. 497 (2013)

[10] S. Ng, J. Plank, Cem. Concr. Res. 42, 847-854 (2012)

[11] J. Plank, D. Zhimin, H. Keller, F. v. Hössle, W. Seidl, Cem. Concr. Res. 40, 45-57 (2010)

[12] L. Ferrari, L. Bernard, F. Deschner, J. Kaufmann, F. Winnefeld, J. Plank, J. Am. Ceram. Soc. 95, 2189-2195 (2012)

[13] S.C.B. Myneni, S.J. Traina, T.J. Logan, Chem. Geol. 148, 1-19 (1998)

[14] K.N. Jallad, M. Santhanam, M.D. Cohen, Cem. Concr. Res. 33, 433-437 (2003)

[15] P.W. Brown, R.D. Hooton, B.A. Clark, Cem. Concr. Compos. 25, 939-945 (2003)

[16] P. Blanc, X. Bourbon, A. Lassin, E.C. Gaucher, Cem. Concr. Res. 40, 1360-1374 (2010) 